\section{Dietary Nutrient Intake Assessment in Maintenance Hemodialysis Patients by Comparing Two Food Record Forms}

Sachiko Nagahama ${ }^{1,2}$, Kunihiro Yamagata ${ }^{3^{*}}$, Chie Saito ${ }^{3}$, Hideto Takahashi ${ }^{4}$, Takahiro Seura ${ }^{5}$, Sumiko Higure ${ }^{6}$ and Tsutomu Nakanishi ${ }^{6}$

${ }^{1}$ Department of Nutritional Management, Sagami Women's University, Kanagawa, Japan

${ }^{2}$ Department of Nephrology, Graduate School of Comprehensive Human Sciences, University of Tsukuba, Ibaraki, Japan

${ }^{3}$ Division of Clinical Medicine, Department of Nephrology, University of Tsukuba, Ibaraki, Japan

${ }^{4}$ National Institute of Public Health, Saitama, Japan

${ }^{5}$ Department of Health and Medical Sciences, Aichi Shukutoku University, Aichi, Japan

${ }^{6}$ Turuma-ekichika-jin Clinic, Kanagawa, Japan

${ }^{*}$ Corresponding author: Kunihiro Yamagata, Division of Clinical Medicine, Department of Nephrology, University of Tsukuba, 1-1-1 Ten-nodai, Tsukuba, Ibaraki, Japan, Tel: +81-29-853-3202; Fax: +81-29-853-3202; Email: k-yamaga@md.tsukuba.ac.jp

Received date: March 12, 2018; Accepted date: April 11, 2018; Published date: April 18, 2018

Copyright: (c) 2018 Nagahama S, et al. This is an open-access article distributed under the terms of the Creative Commons Attribution License, which permits unrestricted use, distribution, and reproduction in any medium, provided the original author and source are credited.

\begin{abstract}
This study aimed to evaluate the accuracy of dietary assessment in hemodialysis patients by comparing the nutrition intake estimated from two food record forms with the actual nutrition intake.

Thirty-nine outpatients receiving stable maintenance hemodialysis in Japan were analyzed. Each patient was provided meals with known nutrient contents for two days and instructed to record the food intake at each meal using a standard food record form (method A) or a semi-quantitative food record form (method B). Each patient underwent two assessments by the two methods in a crossover manner. The concordance proportions between estimated dietary food intake by method A or method B and the actual dietary intake were compared for energy, protein, fat, carbohydrate, potassium, phosphorus, and salt.
\end{abstract}

Estimated energy intake using method B $(96.2 \%)$ was significantly closer $(p<0.05)$ to actual energy intake, compared to method A (90.9\%). However, estimated fat intake using method A (96.9\%) was significantly closer $(p<0.01)$ to actual fat intake compared to method B $(113.4 \%)$. A significant difference $(p<0.05)$ was observed between actual and estimated energy intake by method $A(88.2 \%)$ in females. A significant difference $(p<0.001)$ was observed between actual and estimated total energy intake $(86.7 \%)$ or carbohydrate intake $(85.0 \%)$ for method $A$ in subjects aged $\geq 65$ years.

Method B has improved accuracy compared to method A in estimating energy intake, but still underestimates energy intake. Method B also underestimates carbohydrate intake and overestimates fat intake. Further study is required to improve the accuracy of dietary assessment method.

Keywords: Crossover study; Free entry food record; Semiquantitative food record; Illustrated help

\section{Introduction}

Although the number of patients initiated on dialysis due to end stage renal disease showed a slight decrease in Japan, there is a trend of increase in number of patients on long-term dialysis [1]. Accompanying the aging of dialysis patients and the increase in patients with diabetic nephropathy, various types of nutritional deficiency are commonly found among dialysis patients. Because worsening of nutrition status has a great impact on the complication rate and survival after dialysis initiation, prevention of nutritional deficiency is very important [2-8].

In nutritional management of dialysis patients, dietary assessment is conducted as one component of nutritional assessment aiming to maintain a good nutritional status, and the results are useful for nutrition education. Conventionally, dietary intake has been assessed by methods including food record by patients and dietary recall by patients. For the evaluation of dietary contents in hemodialysis patients, protein and salt intake can be confirmed from objective data obtained by analyzing serum samples before and after dialysis. On the other hand, energy intake can only be estimated from detailed dietary contents [9-11].

However, energy estimated from the information based on food record depends largely on the judgment of the dietitian, with a risk of variability arising in evaluation. Knowing the accurate energy intake in hemodialysis patients is important, because patients with inadequate intake can be taught methods of appropriate energy intake to improve their nutritional status.

With this background, the present study aimed to validate the accuracy of dietary assessment in hemodialysis patients by comparing two food record forms; a conventional free entry record form and a semi-quantitative food record form with illustrated help that we designed. 


\section{Materials and Methods}

\section{Subjects}

Patients receiving stable maintenance hemodialysis on an outpatient basis in three dialysis clinics with 25 or more beds in Kanagawa Prefecture were eligible for enrollment in the study. Inclusion criteria were: aged from 40 to 80 years, at least one-year history of dialysis, capable of eating the provided food, and capable of entering the food record forms.

This study was conducted after obtaining approval from the Medical Ethical Committee of the Faculty of Medicine, University of Tsukuba (No. 74). Before participation, all subjects gave written informed consent after receiving detailed explanations of the purpose and contents of the study.

Of 50 subjects enrolled in the study, 5 subjects who were hospitalized and 3 subjects who withdrew consent during the study period were excluded. According to a crossover design, each subject underwent two dietary assessments: one using a standard food record form (method A) and the other use a semi-quantitative food record form with illustrated help (method B).

Two subjects who used methods other than those instructed and one subject who ate less than one-half of the food provided were excluded from analysis. The remaining 39 subjects (18 males and 21 females) were the subjects of analysis. The food records obtained from all the test meals were analyzed, except when the subject ate less than one-half of the meal provided. Finally, 39 data sets for method A and 39 data sets for method B were analyzed.

\section{Study design}

The study had a crossover design. One half of the subjects were assigned to one of the two dietary assessments (method A and method $B$ ), and then crossed over. The two assessments were conducted with an interval of one month.

The primary outcome measure was the concordance proportion between the energy intake estimated from food record and the actual energy intake. The secondary outcome measures were the concordance proportions between protein, fat, carbohydrate, potassium, phosphorus and salt intake estimated from food record and the calculated actual intake of protein, fat, carbohydrate, potassium, phosphorus and salt.

\section{Dietary assessment}

Regarding the food contents provided in this study, the menus were prepared according to the prescribed nutrition for individual subjects, and checked for food allergy and interaction with concomitant medications. Each subject received six meals (for two days) with known nutrient components via home delivery service. Each patient recorded the food intake at each meal using a standard food record form (method A) or a semi-quantitative food record form (method B).

Each patient underwent two assessments by the two methods in a crossover manner. The percentage of the provided food eaten was calculated as follows. First the quantity of protein component of the provided food was calculated.
Then the protein catabolic rate (PCR) was calculated from the blood urea nitrogen (BUN) levels before and after dialysis. The ratio of PCR to protein content of the provided food [12] was computed as the percentage of food eaten. Next, the amounts of all the nutrients including energy in the food provided were multiplied by the percentage of food eaten to calculate the actual intake of nutrients.

Method A contained the following items: date of entry; meal type divided into "breakfast", "lunch" and "dinner"; and meal component divided into "staple food" and "side dishes". Each subject was free to describe the amounts of the foods eaten. In Method B, the amount of staple food eaten adopted a 3-choice method, from among "all", "onehalf" and "small amount". The dishes were divided into main dish, side dish and appetizer. For each of the dishes, items comprising name of ingredient, amount eaten, and cooking method were included.

To describe the amount of food eaten diagrammatically, a $50-\mathrm{g}$ aluminum foil cup together with the record form were given to each subject before the study, and the subject was instructed to describe the portion eaten by shading the cup printed on the form. The cooking method of each side dish was described as "stewed", "grilled", "pan fried", or "deep fried". The oil absorption rate was assumed to be $5 \%$ for "grilled" and "pan fried", and $12 \%$ for "deep fried", and added to the nutrient intake (Appendix 1 and Appendix 2).

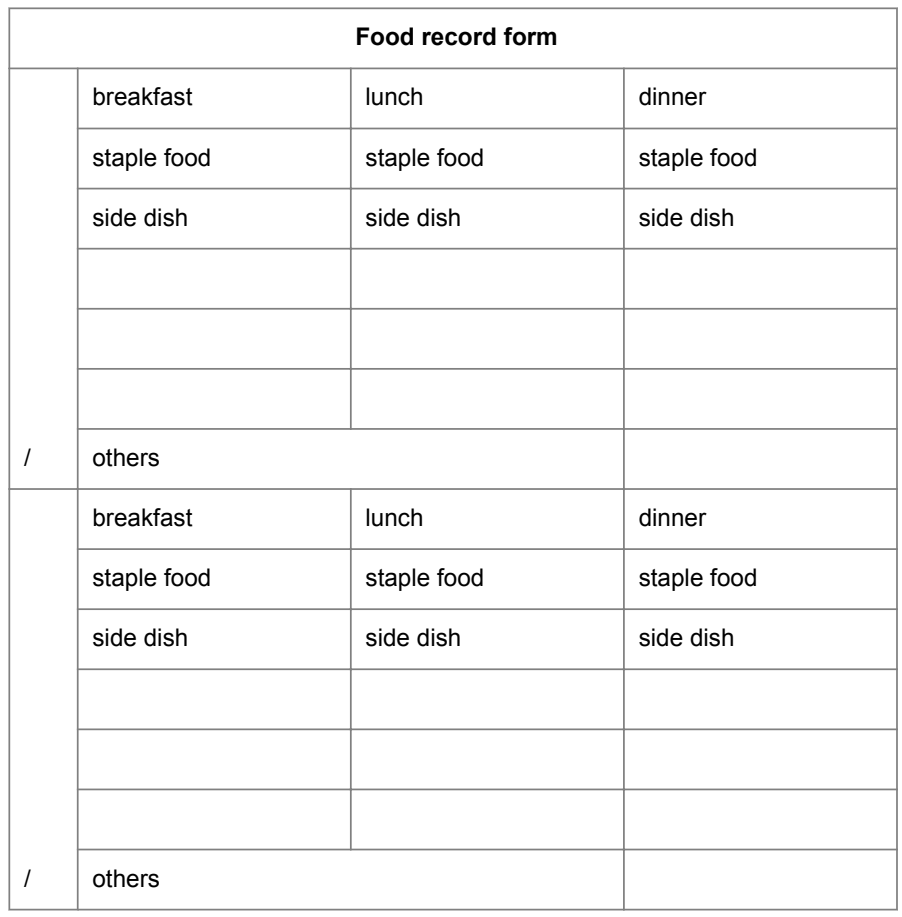

Appendix 1: For the food record form used in method A, meals are divided into "breakfast", "lunch" and "dinner"; and meal components into "staple food" and "dishes". 
Page 3 of 8

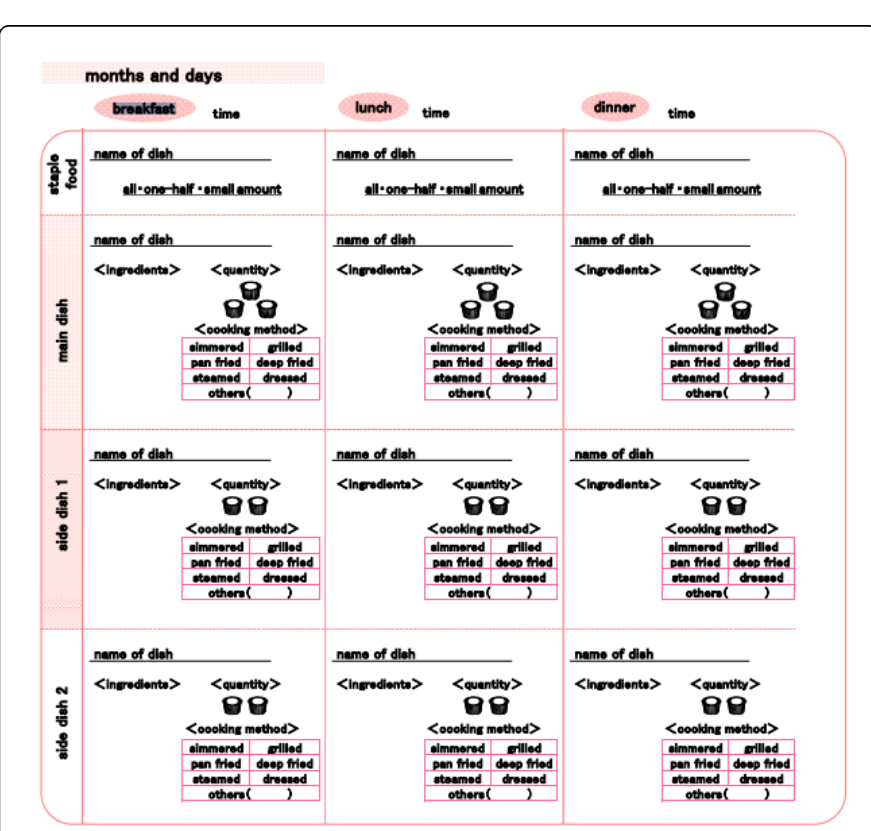

Appendix 2: For the food record form used in method B, improved items are shown in red. First, the amount of staple food is chosen from "all", "one-half" and "small amount". The dishes are divided into main dish, side dish 1 and side dish 2. For each dish, the name of dish, names of eaten is described more accurately and illustrated with diagrams of 50-g aluminum foil cup. The cooking method of each dish is described as "simmered", "grilled", "pan fried", "deep fried", "stewed", "dressed" and "others" to allow more accurate description of amounts of seasonings and oil.

Eight assessors participated in the study. The same patient was evaluated by the same assessor who conducted interviews based on the food record forms and calculated the estimated intake based on the records. Nutrient was calculated according to the Standard Tables of Food Composition in Japan, Fifth Revised and Enlarged Edition [13].

\section{Statistical analyses}

The main outcome measure and secondary outcome measures were analyzed by repeated measures ANOVA. Statistical analyses were performed using SAS 9.3. $\mathrm{P}$ values less than 0.05 were considered to indicate significant difference.

\section{Results}

\section{Background of subjects}

The subjects had a mean age of 64.4 years (range $43-80$ years). The primary disease was diabetes in 21 subjects and non-diabetes in 18 subjects. The mean (range) dialysis duration was 77.9 months (12-324 months); dry weight was 56.7 (39.5-83.0) kg; BMI was 22.6 (16.5-30.4) $\mathrm{kg} / \mathrm{m}^{2}$; prescribed nutrition (mean) was energy $1,762 \mathrm{kcal}$, protein 55.1 $\mathrm{g}$, fat $55 \mathrm{~g}$, carbohydrate $300 \mathrm{mg}$, salt $6.0 \mathrm{~g}$, potassium 1,600 mg and phosphorus $710 \mathrm{mg}$; pre-dialysis systolic blood pressure was 144.9 (102-192) $\mathrm{mmHg}$ and diastolic blood pressure was 66.1 (50-90) $\mathrm{mmHg}$; BUN was $64.6(36.7-100.1) \mathrm{mg} / \mathrm{dL}$; creatinine was 11.3 (5.44-14.88) $\mathrm{mg} / \mathrm{dL}$; albumin was $3.8(3.2-4.4) \mathrm{g} / \mathrm{dL}$; and hemoglobin was $10.7(8.8-12.1) \mathrm{g} / \mathrm{dL}$.

\section{Overall comparison of two methods}

Twenty-seven of 39 subjects (69.2\%) responded eating all the food provided. Table 1 compares the estimated nutrient intake by the two food record forms and the actual intake calculated from the provided food for all 39 subjects. For protein and phosphorus, no significant differences compared to calculated actual intake were observed for both methods, and there were no significant differences between two groups. For fat, the estimated intake was $96.9 \pm 39.7 \%$ of calculated actual intake for method $\mathrm{A}$ and $113.4 \pm 40.9 \%$ of calculated actual intake for method B. Compared to method B, method A estimated fat intake significantly closer to the calculated actual intake $(\mathrm{p}<0.01)$. For carbohydrate, while there was no significant difference between two groups, the estimated intake was $89.4 \pm 21.7 \%$ of calculated actual intake for method $A(\mathrm{p}<0.005)$ and $90.9 \pm 21.5 \%$ of calculated actual intake for method B $(\mathrm{p}<0.05)$, showing significant underestimation for both methods. Finally, for total energy, the estimated intake was $90.9 \pm$ $19.5 \%$ of calculated actual intake for method A and $96.2 \pm 18.9 \%$ of calculated actual intake for method B. Compared to method A, method B estimated total energy intake significantly closer to the calculated actual intake $(\mathrm{p}<0.05)$. For potassium, the estimated intake was $108.7 \pm 24.0 \%$ of calculate intake for method $\mathrm{B}$, with a significant difference compared to the calculated actual potassium intake $(\mathrm{p}<0.05)$. For salt, the estimated intake was $111.4 \pm 41.2 \%$ of calculated actual intake for method A and $102.4 \pm 29.1 \%$ of calculated actual intake for method B. Compared to method A, method B estimated salt intake significantly closer to the calculated actual intake $(\mathrm{p}<0.05)$.

\begin{tabular}{|c|c|c|c|c|c|c|c|c|c|c|c|c|c|c|c|}
\hline & \multicolumn{7}{|c|}{ Method A ( $n=39)$} & \multicolumn{7}{|c|}{ Method B $(n=39)$} & \multirow{3}{*}{\begin{tabular}{|l}
$\begin{array}{l}\text { Method } \\
\text { A vs } \\
\text { Method } \\
\text { B }\end{array}$ \\
\\
P value \\
\end{tabular}} \\
\hline & \multicolumn{2}{|c|}{$\begin{array}{l}\text { Estimated } \\
\text { intake }\end{array}$} & \multicolumn{2}{|c|}{$\begin{array}{l}\text { Calculated } \\
\text { actual intake }\end{array}$} & \multicolumn{3}{|c|}{$\begin{array}{l}\text { Estimated/actual intake } \\
(\%)\end{array}$} & \multicolumn{2}{|c|}{$\begin{array}{l}\text { Estimated } \\
\text { intake }\end{array}$} & \multicolumn{2}{|c|}{$\begin{array}{l}\text { Calculated } \\
\text { actual intake }\end{array}$} & \multicolumn{3}{|c|}{$\begin{array}{l}\text { Estimated/actual intake } \\
(\%)\end{array}$} & \\
\hline & Mean & SD & Mean & SD & Mean & SD & $P$ value & Mean & SD & Mean & SD & Mean & SD & $\begin{array}{l}P \\
\text { value }\end{array}$ & \\
\hline $\begin{array}{l}\text { Total energy } \\
(\mathrm{kcal})\end{array}$ & 1355 & 358.1 & 1488.1 & 219.3 & $90.90 \%$ & 19.5 & $<0.01$ & 1389.9 & 338.2 & 1447.7 & 223 & $96.20 \%$ & 18.9 & 0.22 & $<0.05$ \\
\hline Protein (g) & 45 & 11.9 & 44 & 5.9 & $102.50 \%$ & 23 & 0.51 & 45.5 & 12.1 & 43.3 & 6.5 & $105.20 \%$ & 23 & 0.17 & 0.37 \\
\hline
\end{tabular}


Citation: $\quad$ Nagahama S, Saito C, Takahashi H, Seura T, Higure S, et al. (2018) Dietary Nutrient Intake Assessment in Maintenance Hemodialysis Patients by Comparing Two Food Record Forms. J Nutr Disorders Ther 8: 228. doi:10.4172/2161-0509.1000228

Page 4 of 8

\begin{tabular}{|c|c|c|c|c|c|c|c|c|c|c|c|c|c|c|c|}
\hline Fat (g) & 34 & 13.4 & 36 & 8 & $96.90 \%$ & 39.7 & 0.29 & 38.3 & 13.6 & 34.7 & 7.5 & $113.40 \%$ & 40.9 & $<0.05$ & $<0.01$ \\
\hline $\begin{array}{l}\text { Carbohydrate } \\
\text { (g) }\end{array}$ & 212.8 & 61.7 & 237.2 & 35.1 & $89.40 \%$ & 21.7 & $<0.005$ & 210.4 & 60.4 & 230.9 & 35.9 & $90.90 \%$ & 21.5 & $<0.05$ & 0.77 \\
\hline Potassium (mg) & 1435.7 & 429.7 & 1379.2 & 215.1 & $104.90 \%$ & 29.2 & 0.3 & 1486.8 & 399.7 & 1375 & 229.6 & $108.70 \%$ & 24 & $<0.05$ & 0.21 \\
\hline $\begin{array}{l}\text { Phosphorus } \\
\text { (mg) }\end{array}$ & 640.3 & 173.4 & 636.2 & 96 & $101.20 \%$ & 23.8 & 0.86 & 617 & 160.4 & 627.9 & 101.7 & $99.00 \%$ & 22.5 & 0.62 & 0.49 \\
\hline Salt (g) & 4.7 & 1.7 & 4.4 & 0.7 & $111.40 \%$ & 41.2 & 0.07 & 4.4 & 1.4 & 4.3 & 0.8 & $102.40 \%$ & 29.1 & 0.7 & $<0.05$ \\
\hline
\end{tabular}

All nutrient intake data are presented as amount of intake per day.

For total energy, compared to method A $(90.9 \%)$, method B (96.2\%) estimated total energy intake significantly closer to the calculated actual intake.

For protein and phosphorus, no significant differences between estimated intake actual intake were observed for both methods, and there was no significant difference between two methods. For fat, estimated intake by method A (96.9\%) was significantly closer to actual intake compared to method B (113.4\%).

For carbohydrate, estimated intake was significantly lower than actual intake for both method A (89.4\%) and method B (90.9\%).

Table 1: Comparisons of nutrient intake estimated by Method A vs. Method B.

The data of 27 subjects who reported eating all the provided food were extracted, and the estimated nutrient intake obtained from the food records was compared to the calculated actual intake calculated from the provided food. In this subgroup, both method A and method $\mathrm{B}$ underestimated protein, fat, carbohydrate and total energy intake compared to calculated actual intake, although the underestimation was greater with method A than with method B (data not shown).

\section{Comparison by gender and by age}

Nutrient intake estimated by method A and method B was compared in males and females separately (Table 2). In females, a significant underestimation of total energy was observed for method A (88.2\%), while significant underestimation of carbohydrate intake was found for both method A (86.8\%) and method B (84.5\%). In females, no significant difference between estimated and actual protein uptake was observed, while in males, overestimation of protein was found for both methods. No significant gender differences in estimated intake compared to actual uptake were observed in total energy, fat, carbohydrate, potassium, and phosphorus for both methods. For salt, the estimated intake was $117.1 \pm 34.1 \%$ of calculated actual intake for method A in males, with a significant difference $(\mathrm{p}<0.05)$.

\begin{tabular}{|c|c|c|c|c|c|c|c|c|c|c|c|c|c|c|}
\hline \multicolumn{15}{|c|}{ Method A } \\
\hline & \multicolumn{7}{|c|}{ Males $(n=18)$} & \multicolumn{7}{|c|}{ Females $(n=21)$} \\
\hline & \multicolumn{2}{|c|}{ Estimated intake } & \multicolumn{2}{|c|}{$\begin{array}{l}\text { Calculated actual } \\
\text { intake }\end{array}$} & \multicolumn{3}{|c|}{ Estimated/actual intake (\%) } & \multicolumn{2}{|c|}{ Estimated intake } & \multicolumn{2}{|c|}{$\begin{array}{l}\text { Calculated actual } \\
\text { intake }\end{array}$} & \multicolumn{3}{|c|}{ Estimated/actual intake (\%) } \\
\hline & Mean & SD & Mean & SD & Mean & SD & $P$ value & Mean & SD & Mean & SD & Mean & SD & $P$ value \\
\hline $\begin{array}{l}\text { Total energy } \\
(\mathrm{kcal})\end{array}$ & 1442.6 & 313.7 & 1528 & 208 & $94.30 \%$ & 16.9 & 0.19 & 1284.1 & 379.3 & 1455.8 & 225.4 & $88.20 \%$ & 21.2 & $<0.05$ \\
\hline Protein (g) & 47.1 & 9.3 & 44.7 & 5.2 & $105.20 \%$ & 16.3 & 0.19 & 43.3 & 13.6 & 43.4 & 6.5 & $100.30 \%$ & 27.3 & 0.96 \\
\hline Fat (g) & 35.5 & 13.3 & 37.3 & 8.1 & $97.20 \%$ & 40 & 0.5 & 32.9 & 13.6 & 34.9 & 7.9 & $96.70 \%$ & 39.9 & 0.41 \\
\hline $\begin{array}{l}\text { Carbohydrate } \\
\text { (g) }\end{array}$ & 224.5 & 48.2 & 243.2 & 33.4 & $92.50 \%$ & 16.3 & 0.07 & 203.4 & 69.9 & 232.4 & 36.1 & $86.80 \%$ & 25.2 & $<0.05$ \\
\hline Potassium (mg) & 1455.3 & 365.9 & 1402.1 & 195.4 & $104.00 \%$ & 22.5 & 0.46 & 1419.8 & 479 & 1360.8 & 230.5 & $105.60 \%$ & 33.9 & 0.47 \\
\hline $\begin{array}{l}\text { Phosphorus } \\
\text { (mg) }\end{array}$ & 666.2 & 146.8 & 645.8 & 85.9 & $103.30 \%$ & 19 & 0.49 & 619.4 & 191.5 & 628.5 & 103.9 & $99.60 \%$ & 27.2 & 0.79 \\
\hline Salt (g) & 5.1 & 1.3 & 4.5 & 0.7 & $117.10 \%$ & 34.1 & $<0.05$ & 4.4 & 1.8 & 4.3 & 0.8 & $106.90 \%$ & 46 & 0.56 \\
\hline \multicolumn{15}{|c|}{ Method B } \\
\hline & \multicolumn{7}{|c|}{ Males $(n=18)$} & \multicolumn{7}{|c|}{ Females $(n=21)$} \\
\hline & \multicolumn{2}{|c|}{ Estimated intake } & \multicolumn{2}{|c|}{$\begin{array}{l}\text { Calculated actual } \\
\text { intake }\end{array}$} & \multicolumn{3}{|c|}{ Estimated/actual intake (\%) } & \multicolumn{2}{|c|}{ Estimated intake } & \multicolumn{2}{|c|}{$\begin{array}{l}\text { Calculated actual } \\
\text { intake }\end{array}$} & \multicolumn{3}{|c|}{ Estimated/actual intake (\%) } \\
\hline
\end{tabular}


Citation: $\quad$ Nagahama S, Saito C, Takahashi H, Seura T, Higure S, et al. (2018) Dietary Nutrient Intake Assessment in Maintenance Hemodialysis

Page 5 of 8

\begin{tabular}{|c|c|c|c|c|c|c|c|c|c|c|c|c|c|c|}
\hline & Mean & SD & Mean & SD & Mean & SD & $P$ value & Mean & SD & Mean & SD & Mean & SD & $P$ value \\
\hline $\begin{array}{l}\text { Total energy } \\
\text { (kcal) }\end{array}$ & 1490.9 & 291.4 & 1493 & 201.7 & $99.70 \%$ & 14.4 & 0.97 & 1294.3 & 355.1 & 1404.7 & 236.1 & $92.90 \%$ & 22 & 0.11 \\
\hline Protein (g) & 48.2 & 11.3 & 44.6 & 5.6 & $108.20 \%$ & 21.6 & 0.1 & 43 & 12.5 & 42.1 & 7 & $102.30 \%$ & 24.3 & 0.7 \\
\hline Fat $(\mathrm{g})$ & 39 & 14.6 & 35.5 & 7.2 & $111.30 \%$ & 42.1 & 0.21 & 37.7 & 12.8 & 33.9 & 7.7 & $115.30 \%$ & 40.3 & 0.12 \\
\hline $\begin{array}{l}\text { Carbohydrate } \\
\text { (g) }\end{array}$ & 232.9 & 49.3 & 238.6 & 33.9 & $97.60 \%$ & 16.6 & 0.57 & 189.1 & 62.7 & 223.6 & 36.6 & $84.50 \%$ & 23.7 & $<0.005$ \\
\hline Potassium (mg) & 1482.3 & 306.1 & 1413.4 & 200.1 & $105.60 \%$ & 18.8 & 0.26 & 1491 & 476 & 1338.5 & 251.6 & $111.60 \%$ & 28 & 0.08 \\
\hline $\begin{array}{l}\text { Phosphorus } \\
\text { (mg) }\end{array}$ & 632.6 & 164.9 & 650.2 & 91.6 & $97.70 \%$ & 22.4 & 0.58 & 602.3 & 156.7 & 606.6 & 107.3 & $100.30 \%$ & 22.8 & 0.89 \\
\hline Salt (g) & 4.5 & 1.2 & 4.5 & 0.7 & $99.60 \%$ & 24.5 & 0.85 & 4.3 & 1.6 & 4.2 & 0.9 & $105.00 \%$ & 33 & 0.52 \\
\hline
\end{tabular}

Table 2: Comparison of nutrient intake of Method A vs. Method B, by gender.

The subjects were stratified into two age groups: below 65 years, and 65 years and above, and nutrient intake estimated by method $\mathrm{A}$ and method B were compared in the two age groups (Table 3). In subjects aged below 65 years, overestimation of protein was obvious. On the other hand, subjects aged 65 years and above showed underestimation of protein intake by method A, but no significant difference by method B.

\begin{tabular}{|c|c|c|c|c|c|c|c|c|c|c|c|c|c|c|}
\hline \multicolumn{15}{|c|}{ Method A } \\
\hline & \multicolumn{7}{|c|}{ Below 65 years $(n=17)$} & \multicolumn{7}{|c|}{65 years and above $(n=22)$} \\
\hline & \multicolumn{2}{|c|}{ Estimated intake } & \multicolumn{2}{|c|}{$\begin{array}{l}\text { Calculated actual } \\
\text { intake }\end{array}$} & \multicolumn{3}{|c|}{$\begin{array}{l}\text { Estimated/actual intake } \\
(\%)\end{array}$} & \multicolumn{2}{|c|}{ Estimated intake } & \multicolumn{2}{|c|}{$\begin{array}{l}\text { Calculated actual } \\
\text { intake }\end{array}$} & \multicolumn{3}{|c|}{ Estimated/actual intake (\%) } \\
\hline & Mean & SD & Mean & SD & Mean & SD & $P$ value & Mean & SD & Mean & SD & Mean & SD & $P$ value \\
\hline $\begin{array}{l}\text { Total energy } \\
\text { (kcal) }\end{array}$ & 1411.8 & 398.4 & 1453.1 & 264.9 & $96.70 \%$ & 19 & 0.63 & 1313.7 & 324.2 & 1513.5 & 178.2 & $86.70 \%$ & 19 & $<0.001$ \\
\hline Protein $(\mathrm{g})$ & 47.9 & 13.5 & 42.7 & 7.3 & $111.90 \%$ & 22.8 & 0.06 & 42.9 & 10.2 & 44.9 & 4.5 & $95.60 \%$ & 20.8 & 0.24 \\
\hline Fat $(g)$ & 36.5 & 12 & 35.5 & 9.3 & $106.80 \%$ & 34 & 0.71 & 32.2 & 14.2 & 36.3 & 7.1 & $89.80 \%$ & 42.3 & 0.09 \\
\hline $\begin{array}{l}\text { Carbohydrate } \\
\text { (g) }\end{array}$ & 223 & 68.1 & 230.8 & 42.6 & $95.40 \%$ & 22 & 0.58 & 205.5 & 56.2 & 241.9 & 28.1 & $85.00 \%$ & 20.7 & $<0.001$ \\
\hline Potassium (mg) & 1528.1 & 512.1 & 1342.6 & 259.5 & $114.80 \%$ & 33.9 & 0.07 & 1368.4 & 349.4 & 1405.9 & 174.5 & $97.70 \%$ & 23.1 & 0.52 \\
\hline $\begin{array}{l}\text { Phosphorus } \\
\text { (mg) }\end{array}$ & 675.9 & 198.8 & 617.4 & 110.4 & $109.80 \%$ & 25.1 & 0.15 & 614.5 & 149.4 & 649.9 & 82.7 & $95.00 \%$ & 21 & 0.17 \\
\hline Salt (g) & 4.8 & 1.7 & 4.2 & 0.9 & $117.40 \%$ & 42.6 & 0.07 & 4.7 & 1.7 & 4.5 & 0.6 & $107.10 \%$ & 40 & 0.41 \\
\hline \multicolumn{15}{|c|}{ Method B } \\
\hline & \multicolumn{7}{|c|}{ Below 65 years $(n=17)$} & \multicolumn{7}{|c|}{65 years and above $(n=22)$} \\
\hline & \multicolumn{2}{|c|}{ Estimated intake } & \multicolumn{2}{|c|}{$\begin{array}{l}\text { Calculated actual } \\
\text { intake }\end{array}$} & \multicolumn{3}{|c|}{$\begin{array}{l}\text { Estimated/actual } \\
(\%)\end{array}$} & \multicolumn{2}{|c|}{ Estimated intake } & \multicolumn{2}{|c|}{$\begin{array}{l}\text { Calculated actual } \\
\text { intake }\end{array}$} & \multicolumn{3}{|c|}{ Estimated/actual intake (\%) } \\
\hline & Mean & SD & Mean & SD & Mean & SD & $P$ value & Mean & SD & Mean & SD & Mean & SD & $P$ value \\
\hline $\begin{array}{l}\text { Total energy } \\
\text { (kcal) }\end{array}$ & 1357.4 & 366.7 & 1434.5 & 232.3 & $95.60 \%$ & 23 & 0.32 & 1414.7 & 317.1 & 1457.7 & 217.9 & $96.70 \%$ & 15.3 & 0.47 \\
\hline
\end{tabular}




\begin{tabular}{|l|l|l|l|l|l|l|l|l|l|l|l|l|l|l|}
\hline Protein (g) & 45.2 & 12 & 43.3 & 6.8 & $105.30 \%$ & 23.8 & 0.42 & 45.7 & 12.4 & 43.4 & 6.3 & $105.10 \%$ & 22.8 & 0.28 \\
\hline Fat (g) & 38.3 & 12.9 & 34.9 & 7.3 & $114.70 \%$ & 42.4 & 0.2 & 38.3 & 14.3 & 34.6 & 7.7 & $112.30 \%$ & 40.3 & 0.14 \\
\hline $\begin{array}{l}\text { Carbohydrate } \\
(\mathrm{g})\end{array}$ & 200.8 & 67.2 & 227.4 & 37.3 & $88.40 \%$ & 25.4 & 0.05 & 217.8 & 54.3 & 233.6 & 35 & $92.80 \%$ & 18.1 & 0.12 \\
\hline Potassium (mg) & 1563.9 & 447.7 & 1375.5 & 235.5 & $114.40 \%$ & 27.9 & $<0.05$ & 1428 & 353.2 & 1374.6 & 227.8 & $104.30 \%$ & 19.8 & 0.41 \\
\hline $\begin{array}{l}\text { Phosphorus } \\
\text { (mg) }\end{array}$ & 628.4 & 146 & 626.8 & 103.7 & $101.60 \%$ & 21.9 & 0.96 & 608.3 & 171.7 & 628.7 & 101.5 & $97.10 \%$ & 23 & 0.51 \\
\hline
\end{tabular}

Table 3: Comparison of nutrient intake of Method A vs. Method B, by age group.

For potassium, the estimated intake was $114.4 \pm 27.9 \%$ of calculated actual intake for method $\mathrm{B}$ in subjects aged below 65 years, with a significant difference compared to the actual potassium intake $(\mathrm{p}<0.05)$.

In subjects aged 65 years and above, however, the estimated total energy intake was $86.7 \% \pm 19.0 \%$ of calculated actual intake for method A, showing a significant underestimation compared to actual energy intake $(p<0.001)$. For carbohydrate, the estimated intake was $85.0 \pm 20.7 \%$ of calculated actual intake for method A, again showing a significant underestimation compared to the actual carbohydrate intake $(\mathrm{p}<0.001)$.

\section{Discussion}

In dietary assessment, dietary intake is assessed by methods including food record, 24-hour dietary recall, semi-quantitative food frequency questionnaire (FFQ), and dietary history [14-22]. The 24hour recall and FFQ are considered to pose less burden on the respondent, but calculation of precise dietary intake is difficult. A study that compared the accuracy of energy intake assessed using a brief administered dietary history questionnaire and diet record in relation to psychosocial support from dialysis staff found underestimation in men and employed subjects [23].

For the food record method, visual educational materials such as illustrations and photographs are useful to explain what should be recorded, and these materials are expected to promote understanding and continued recording. Comparing methods $\mathrm{A}$ and $\mathrm{B}$ in the present study, method A requires no prior instructions, but has the demerits that quantification of the intake amount and evaluation of condiments according to cooking method are not possible. On the other hand, method B has several additional features: three choices for the quantity of staple food eaten, semi-quantification of the amounts of dishes eaten expressed by aluminum foil cup, and evaluation of condiments according to cooking method. We thus compared the performance of method B with method A.

Overestimation of fat by method B is probably because method B facilitates description of names and amounts of fat-rich food ingredients and cooking methods. On the other hand, both method A and method B estimated carbohydrate intake significantly lower than the calculated actual intake, suggesting underestimation of staple food intake. In Method B, the amount of staple food eaten was reported by choosing from "all", "one-half" and "small amount", which should allow assessment closer to the calculated actual intake than method A. In subjects who did not eat all the provided food, the difference between estimated carbohydrate intake and calculated actual carbohydrate intake might be due to self-restriction of carbohydrate possibly due to a past history of dietary therapy. Since $53.8 \%$ of all the patients had diabetes as the underlying disease, it is possible that many of the patients do not understand the switch from the energy restricted diet prescribed in the past to the present dialysis diet. A subgroup analysis of 27 subjects who reported eating all the provided food showed that although both method A and method B underestimated carbohydrate intake, method B provided a closer estimate. This result suggests that method B improves the accuracy of carbohydrate intake estimation when patients comply with the prescribed diet.

Although both methods underestimated total energy intake, method B provided a closer estimate compared to the calculated actual intake in all subjects and in the subgroup that reported eating all the provided food. This result indicates that method $\mathrm{B}$ improves the accuracy of total energy estimation, but underestimation remains an issue. Previous studies have reported underestimation of energy intake in dietary assessment [24-26]. The factors associated with underestimation of energy intake include old age, dietary restrictions including energy and fat, smoking, socioeconomic status, and population study. Hence, further studies of respondent personality and mechanisms leading to underestimation are required.

In the present study on the effect of gender, the estimated protein intake by both methods were identical to the calculated actual intake in females. In general, females are more knowledgeable about food ingredients and cooking methods and have more experience than males [23]. However, the same results were obtained for methods A and $B$ in females, suggesting that there is little benefit from using method B in females.

In patients aged 65 years and above, estimated intake by method B was closer to the calculated actual intake, showing clearly improved accuracy compared to method A. Thus, while food record entered by free description (method A) is adequate in patients aged below 65 years, this method lacks accuracy in patients aged 65 years and above and method B is superior in accuracy in this age group. 
Compared to method A, method B estimated salt intake significantly closer to the calculated actual salt intake. Method B that facilitates the description of names of dishes, illustrates quantities, and allows description of cooking method may be useful in assessing the quantities of condiments including salt used in cooking.

To increase the accuracy of dietary intake estimation of the food record method, refinement of the record form used in dietary assessment is necessary. The form should be revised such that it is easy and convenient to record, and the wordings are easy to understand by the patients, and that it should satisfy the patients' needs [27]. Especially for method A used in the present study, differences were observed in older patients. Thus, the recoding method should be revised taking into consideration the effects of past history of dietary therapy in patients with underestimated intake, history of receiving nutritional counseling, and psychological factors. In addition to gender difference and age difference, the approach in food record method considering factors such as medical history, clinical data, conditions of dialysis diet (prescribed nutrition), independence in food preparation and study period, as well as thorough prior instructions may contribute to establish a highly sensitive dietary nutrient intake assessment method.

Finally, when comparing the two methods in terms of the efforts and time required of the recorder (time taken for the patient and family to enter the record) and the result interpreter (time taken for the dietitian to calculate the nutrition intake from the patient's record and interview), the superiority of the semi-quantitative food record with illustrated help can be envisaged. Further detailed studies are warranted.

This study has a limitation. This study was a pilot study with a small sample size. To validate whether our semi-quantitative method can be applied to clinical use, further study investigating a large number of patients in the clinical setting is needed.

In dietary assessment for hemodialysis patients, although our novel semi-quantitative method improved accuracy compared to the standard method, underestimation of energy intake compared to the actual energy intake from the food provided was observed. The main features of the semi-quantitative food record with illustrated help are that it illustrates the amount of food eaten and allows detailed descriptions of cooking method. Using this food record, although a tendency of improved accuracy for the estimation of total energy and salt intake was observed, further study is needed to increase the accuracy of estimating fat and carbohydrate. In the future, further studies are needed to establish a simpler and more effective food record method that considers gender difference and age difference, together with the background of the dialysis patients including their dietary condition, past experience of dietary therapy, past history of receiving nutritional counseling, and psychological factors.

In conclusion, the semi-quantitative method in this study is easy and accurate, and is potentially useful for evaluating energy intake, especially in females and aged hemodialysis patients.

\section{Acknowledgements}

The manuscript was prepared with translation assistance provided by Dr. Teresa Nakatani. The authors would like to thank Yoshiko Miyamoto and Chinatsu Amano, former research associates of Department of Nutritional Management, Faculty of Nutritional
Science, Sagami Women's University for their cooperation in data management during the study.

\section{Conflict of Interest}

The authors declare no potential conflicts of interests.

\section{Funding}

This research was supported by AMED under Grant Number JP17ek0310005.

\section{References}

1. Nakai S, Watanabe Y, Masakane I, Wada A, Shoji T, et al. (2013) An overview of regular dialysis treatment in Japan (as of 31 December 2011). Ther Apher Dial 17: 567-611.

2. Bergstrom J (1995) Nutrition and mortality in hemodialysis. J Am Soc Nephrol 6: 1329-1341.

3. Qureshi AR, Alvestrand A, Divino-Filho JC, Gutierrez A, Heimbürger O, et al. (2002) Inflammation, malnutrition, and cardiac disease as predictors of mortality in hemodialysis patients. J Am Soc Nephrol 13: S28-S36.

4. Yamada K, Furuya R, Takita T, Maruyama Y, Yamaguchi Y, et al. (2008) Simplified nutritional screening tools for patients on maintenance hemodialysis. Am J Clin Nutr 87: 106-113.

5. Owen WF, Lew NL, Liu Y, Lowrie EG, Lazarus JM (1993) The urea reduction ratio and serum albumin concentration as predictors of mortality in patients undergoing hemodialysis. N Engl J Med 329: 1001-1006.

6. Noori N, Kalantar-Zadeh K, Kovesdy CP, Murali SB, Bross R, et al. (2010) Dietary potassium intake and mortality in long-term hemodialysis patients. Am J Kidney Dis 56: 338-347.

7. Kalantar-Zadeh K, Kovesdy CP, Bross R, Benner D, Noori N, et al. (2011) Design and development of a dialysis food frequency questionnaire. J Ren Nutr 21: 257-262.

8. Beberashvili I, Azar A, Sinuani I, Kadoshi H, Shapiro G, et al. (2013) Comparison analysis of nutritional scores for serial monitoring of nutritional status in hemodialysis patients. Clin J Am Soc Nephrol 8: 443-451.

9. Tohmas FP, Nan ML, Edmund GL (1983) Comparison of the study groups in the national cooperative dialysis study and a description of morbidity, mortality and patient withdrawal. Kidney Int 13(Suppl): S42S9.

10. Nakao T, Matsumoto H, Okada T, Kanazawa Y, Yoshino M, et al. (2003) Nutritional management of dialysis patients: balancing among nutrient intake, dialysis dose, and nutritional status. Am J Kidney Dis 41(3 Suppl 1): $133-136$

11. Nelson M (2000) Methods and validity of dietary assessment. In: Human Nutrition and Dietetics, Churchill Livingstone 311-331.

12. Depner TA, Daugirdas JT (1996) Equations for normalized protein catabolic rate based on two-point modeling of hemodialysis urea kinetics. J Am Soc Nephrol 7: 780-785.

13. [No authors Listed] (2010) Ministry of Education, Culture, Sports, Science and Technology-Japan. Standard Tables of Food Composition in Japan, Fifth Revised and Enlarged Edition.

14. Roddam AW, Spencer E, Banks E, Beral V, Reeves G, et al. (2005) Reproducibility of a short semi-quantitative food group questionnaire and its performance in estimating nutrient intake compared with a 7-day diet diary in the Million Women Study. Public Health Nutr 8: 201-213.

15. Bross R, Noori N, Kovesdy CP, Murali SB, Benner D, et al. (2010) Dietary assessment of individuals with chronic kidney disease. Semin Dial 23: 359-364. 
Citation: $\quad$ Nagahama S, Saito C, Takahashi H, Seura T, Higure S, et al. (2018) Dietary Nutrient Intake Assessment in Maintenance Hemodialysis

16. Griffiths A, Russell L, Breslin M, Russell G, Davies S (1999) A comparison of two methods of dietary assessment in peritoneal dialysis patients. J Ren Nutr 9: 26-31.

17. Bingham SA, Gill C, Welch A, Day K, Cassidy A, et al. (1994) Comparison of dietary assessment methods in nutritional epidemiology: weighed records v. $24 \mathrm{~h}$ recalls, food-frequency questionnaires and estimated-diet record. Br J Nutr 72: 619-643.

18. Millen AE, Tooze JA, Subar AF, Kahle LL, Schatzkin A, et al. (2009) Differences between food group reports of low-energy reporters and nonlow-energy reporters on a food frequency questionnaire. J Am Diet Assoc 109: 1194-1203.

19. Thomson CA, Giuliano A, Rock CL, Ritenbaugh CK, Flatt SW, et al. (2003) Measuring dietary change in a diet intervention trial: comparing food frequency questionnaire and dietary recalls. Am J Epidemiol 157: 754-762.

20. Hill RJ, Davies PS (2001) The validity of self-reported energy intake as determined using the doubly labeled water technique. Br J Nutr 85: 415-430.

21. Ferriolli E, Pfrimer K, Moriguti JC, Lima NK, Moriguti EK, et al. (2010) Under-reporting of food intake is frequent among Brazilian free-living older persons: a doubly labeled water study. Rapid Commun Mass Spectrom 24: 506-510.

22. Mahabir S, Baer DJ, Giffen C, Subar A, Campbell W, et al. (2006) Calorie intake misreporting by diet record and food frequency questionnaire compared to doubly labeled water among postmenopausal women. Eur J Clin Nutr 60: 561-565.

23. Yokoyama Y, Sasaki S, Suzukamo Y, Yamazaki S, Takegami M, et al. (2013) Interpersonal psychosocial factors associated with underreported dietary energy intake in hemodialysis patients. J Ren Nutr 23: 37-44.

24. Okubo H, Sasaki S, Rafamantanantsoa HH, Ishikawa-Takata K, Okazaki $\mathrm{H}$, et al. (2007) Validation of self-reported energy intake by a selfadministered diet history questionnaire using the doubly labeled water method in 140 Japanese adults. Eur J Clin Nutr 62: 1343-1350.

25. Johansson G, Wikman A, Ahren AM, Hallmans G, Johansson I (2001) Underreporting of energy intake in repeated 24-hour recalls related to gender, age, weight status, day of interview, educational level, reported food intake, smoking habits and area of living. Public Health Nutr 4: 919-927.

26. Martin GS, Tapsell LC, Denmeade S, Batterham MJ (2003) Relative validity of a diet history interview in an intervention trial manipulating dietary fat in the management of type II diabetes mellitus. Prev Med 36: 420-428.

27. Poslusna K, Ruprich J, de Vries JH, Jakubikova M, van't Veer P (2009) Misreporting of energy and micronutrient intake estimated by food records and 24 hour recalls, control and adjustment methods in practice. Br J Nutr 101(Suppl 2): S73-S85. 